\title{
Field testing of inter- and intraspecific coalescence among mid-intertidal red algae
}

\author{
Bernabé Santelices*, Diego Aedo, Marcela Hormazábal, Verónica Flores \\ Departamento de Ecología, Facultad de Ciencias Biológicas, Pontificia Universidad Católica de Chile, Casilla 114-D, \\ Santiago, Chile
}

\begin{abstract}
Although spores, sporelings and juveniles of many ecologically important and competitively dominant seaweed species inhabiting intertidal and shallow subtidal habitats may coalesce, it is unknown whether coalescence among holdfasts of well-established clumps occurs naturally in the field. Using a combination of field and ultrastructural studies, we evaluate if inter- and intraspecific coalescence occurs between clumps of Mazzaella laminarioides and Nothogenia fastigiata and, if so, whether such a process modifies clump shapes and sizes. Interspecific encounters always resulted in cell compression and destruction of the contacting tissues and in the eventual mortality of 1 of the partners (in this case N. fastigiata). In contrast, intraspecific encounters in both species always resulted in coalescence. In these field populations, coalescence seems to be frequent and dynamic and is probably modulated by other community structuring mechanisms such as grazing, abiotic extremes, and mussel recruitment. This field demonstration of coalescence suggests that many intertidal and subtidal populations of coalescing Rhodophyta might be chimeric.
\end{abstract}

KEY WORDS: Chimerism · Coalescence $\cdot$ Competition $\cdot$ Algae shape Intertidal habitats $\cdot$ Mazzaella Nothogenia $\cdot$ Red seaweeds Resale or republication not permitted without written consent of the publisher

\section{INTRODUCTION}

For well over a century, zoologists working with colonial animals have described fusion of different colonies to produce a chimeric entity (Giard 1872, Bancroft 1903). Such a process is common among all major groups of sessile modular animals that dominate marine, hard-substrate faunas, including sponges, hydroids, corals, bryozoan and ascidians (Grosberg 1988, Hughes 1989, Maldonado 1998). The development and occurrence of chimeras could have profound consequences for ecological processes of recruitment, growth, spatial competition and gamete exchange (Sommerfeldt \& Bishop 1999). Yet, because unitary organisms are preferentially studied, we still know little about the consequences of fusion.

Among seaweeds, an equivalent process producing composite, chimeric entities has been known for the last $70 \mathrm{yr}$, i.e. coalescence (Rosenvinge 1931, Jones 1956). Spores of coalescing red algae generally germi- nate, forming a disk that later grows into a crust. Crusts in physical contact with each other may establish cellular connections (secondary pit connections) and form a common external wall. Thus, after coalescence between compatible partners, there is no visible evidence (via naked eye or light microscopy) that the new thallus is the product of 2 or more genotypes and that the resulting 'individual' is in fact a genetically polymorphic, chimeric organism (Santelices et al. 1996).

The process of coalescence has been documented in nearly 3 dozen species in the orders Ahnfeltiales, Corallinales, Gigartinales, Gracilariales, Halymeniales, Palmariales and Rhodymeniales of the division Rhodophyta (see Santelices et al. 1999 for review). Many taxa in these orders (e.g. species in the genera Ahnfeltia, Ahnfeltiopsis, Callophyllis, Champia, Chondrus, Corallina, Endocladia, Fosliella, Gastroclonium, Gigartina, Gracilaria, Grateloupia, Gymnogongrus, Hildenbrandia, Hypnea, Iridaea, Lithophyllum, Lithothamnion, Masto- 
carpus, Mazzaella, Microcladia, Plocamium, Petrocelis, Phyllophora, Porolithon, Rhodymenia, Sarcothalia, Schizymenia) are important space users in many middle to low intertidal and shallow subtidal habitats at diverse latitudes (see descriptions in Stephenson \& Stephenson 1972, Mathieson \& Nienhuis 1991 and Raffaelli \& Hawkins 1996) and, as for colonial animals, it is possible that coalescence may affect key ecological processes such as recruitment, competitive ability and susceptibility to grazing. However, coalescence has only been described from laboratory cultures and in connection with spores and germlings (see Santelices et al. 1999). A first step in evaluating the relative importance of coalescence is to determine whether the process occurs among well-established clumps in the field and whether it is restricted to conspecific partners or also includes interspecific fusions. While most previous studies have described intraspecific coalescence, a recent study by Maggs \& Cheney (1990) described successful coalescence in mixed spore cultures of 2 different species of Gracilaria.

Using a combination of ecological and ultrastructural studies, we here evaluate the natural occurrence of inter- and intraspecific coalescence in rocky, midintertidal habitats of central Chile dominated in cover and biomass by 2 red algae species, Mazzaella laminarioides (Bory) Fredericq and Nothogenia fastigiata (Bory) Parkinson. Specifically, we evaluate whether coalescence occurs among well-established clumps in the field or if it is restricted to sporeling stages only. In addition, we evaluate if it is a strictly intraspecific response or whether it involves clumps of different species. By combining data on the frequency distributions of inter-clump distances, together with holdfast growth rates and length of the growth season, we calculate the frequency of coalescence in these midintertidal red algae populations.

\section{MATERIALS AND METHODS}

Study sites. Field studies were carried out at 2 localities in central Chile: Caleta Maitencillo $\left(32^{\circ} 39^{\prime} \mathrm{S}\right.$, $71^{\circ} 29^{\prime} \mathrm{W}$ ), approximately $100 \mathrm{~km}$ north of Valparaíso, and Topocalma $\left(34^{\circ} 05^{\prime} \mathrm{S}, 71^{\circ} 58^{\prime} \mathrm{W}\right)$, approximately $120 \mathrm{~km}$ south of San Antonio. At both sites, rocky platforms and outcrops of large and small boulders receive the direct effects of onshore waves and are surrounded by sandy beaches. The shallow subtidal suffers periodic episodes of sand inundation, preventing high grazer densities and favoring the development of algae associations with sand-resistant perennial phases (Santelices 1990a, 1991). Along much of central Chile, a mixed vegetational belt of Mazzaella laminarioides and Nothogenia fastigiata attains high substratum cover and biomass in this type of habitat (Santelices \& Norambuena 1987). At Maitencillo, the belt extends from 0.5 to $1.6 \mathrm{~m}$ above chart datum (lowest low water), while at Topocalma it extends from 0.7 to $1.4 \mathrm{~m}$ above chart datum. Algae cover at both sites decreases with increasing tidal height, from $80-100 \%$ in the lower (about $0.5 \mathrm{~m}$ ) zone to $10-20 \%$ in the upper zone. Intermixed with these 2 dominant seaweed species, and increasing in importance in an upshore direction, are single or mixed-species associations of the black mussel Perumytilus purpuratus, acorn barnacles and ephemeral foliose algae such as Enteromorpha compressa (Linnaeus) Greville, Ulva rigida (C. Agardh) Thuret and Porphyra columbina Montagne.

Species. In the field, clumps of Mazzaella laminarioides consist of up to 50 erect blades, with rather long, often canaliculated stipes that grow from an irregular or dome-shaped holdfast. Erect fronds may be up to $30 \mathrm{~cm}$ long and $5 \mathrm{~cm}$ wide. However, usually only 1 or 2 blades per plant reach a large size and there is a tendency for larger and thicker blades to be located closer to the center of the holdfast, generating size inequalities among the fronds arising from the same disc (Martínez \& Santelices 1992, Santelices et al. 1999). In this species, growth meristems are located along the border of the disc and at the base and borders of erect fronds.

In contrast, clumps of Nothogenia fastigiata have 2 morphologies. The tetrasporophytic phase consists of a bright red, thin crust that overgrows rocky surfaces, especially in shaded areas. The gametophytic phase has several fan-shaped, dichotomously branched erect axes, with a cuneate base and broad tips, which attach to the substratum by a small holdfast. After reproduction, erect axes disappear while the basal crust is perennial. In central Chile, sexual gametes are produced from January to September (Hoffmann \& Santelices 1997). Frequently, the basal crust of the gametophytic phase develops on top of the sporophytic crust. After loss of the erect axes, it is often impossible to distinguish the karyological phase of any given crust in the field. In this study, all measurements of interplant distances and growth rates of tagged individuals (see following section) were made on gametophytes presenting a distinct base and erect axes.

Ecological studies. The ecological studies included measuring the abundance of contacting partners in the field, tagging neighboring clumps and monitoring their holdfast dimensions for a 31 mo period (June 1999 to December 2001) recording the frequency distribution of inter-clump distances in the 2 populations at both study sites, and measuring the distribution of erect axes in clumps of Mazzaella laminarioides before and after holdfast contact.

Abundance of contacting partners: To characterize temporal variation in the potential incidence of coales- 
cence in the field, we conducted monthly surveys of the abundance of contacting partners (clumps in physical contact) at each site from June (Maitencillo) or August (Topocalma) 1999 to December 2001. Thirty quadrats of $900 \mathrm{~cm}^{2}$ each were systematically placed along 6 vertical transects that extended from the upper to the lower limits of the Mazzaella laminarioidesNothogenia fastigiata belt. At each site, 2 replicate transects 1.2 to $1.5 \mathrm{~m}$ long and 2 to $4 \mathrm{~m}$ apart were placed on each of 3 rocky outcrops separated by sand beaches of 50 to $150 \mathrm{~m}$ in horizontal extent. Rocky outcrops consisted of platforms at Topocalma, while boulder fields were surveyed at Maitencillo. Within each quadrat, we identified and counted the number of all algae clumps and separately recorded the number of contacting partners (clumps with holdfasts within 2 $\mathrm{mm}$ of each other). Data were averaged for each outcrop at each site and expressed as the percentage of the clump population exhibiting a high probability of inter- or intraspecific contact (contacting partners).

Temporal changes in holdfast growth: To estimate temporal changes in holdfast growth and quantify the proportion of successful contacts, a total of 100 pairs of clumps were tagged at each site. Tagging consisted of iron screws placed in countersunk holes drilled in the rock next to algae clumps and of plastic tags (FTF 69 Fingerling tags) attached to fronds. Because of natural density differences in species pairs, the number of replicate pairs and initial distance between partners varied among species combinations. Initial tagging included 70 pairs of conspecific clumps of Mazzaella laminarioides with inter-holdfast distances between 2 and $40 \mathrm{~mm}, 20$ pairs of M. laminarioides-Nothogenia fastigiata with inter-holdfast distances between 2 and $15 \mathrm{~mm}$, and 10 pairs of conspecific neighbors of $N$. fastigiata with inter-holdfast distances between 2 and $10 \mathrm{~mm}$. Each month, the distance between holdfasts of tagged partners was measured. New clumps were tagged as necessary to cover any losses. With few exceptions, normal monthly losses were no greater than 3 to 5 clumps at each site, but there was seasonal variation in loss rates at both sites. The $N$. fastigiata population of tagged plants lost their erect axes between January and May 2000 (57 out of 63 tagged pairs at both sites) and again in April 2001 (36 out of 40 tagged pairs). On the other hand, the tagged population of $M$. laminarioides was severely reduced in March (Topocalma; 26 out of 43 pairs) and June (Maitencillo; 20 out of 70 pairs) 2000 and then in April 2001 (both sites: 50 out of 124 pairs). These reductions appear to have resulted from harvesting by fishermen. In central and southern Chile, M. laminarioides is commercially harvested for carrageenan production (Santelices \& Norambuena 1987). Generally, the largest blades are picked by hand during harvesting, but the holdfast may also be damaged.

Pooling initial and later taggings, a total of 127 pairs of conspecific clumps of Mazzaella laminarioides were monitored in Maitencillo and 91 in Topocalma (see Table 1). The respective numbers for the conspecific pairs of Nothogenia fastigiata were 34 in Maitencillo and 39 in Topocalma, while the total number of tagged pairs for the interspecific relationship ( $M$. laminarioides $-N$. fastigiata) were 46 in Maitencillo and 25 in Topocalma.

Inter-clump distances: Inter-clump distances were measured to calculate the percent of the populations of Mazzaella laminarioides and Nothogenia fastigiata likely to establish inter- or intraspecific contacts within 1 or 2 growing seasons at the expansion rates exhibited by these populations. Distances were measured at the end of the study period (December 2001) using the 'nearest-neighbor method' (Cottam et al. 1953, Cottam \& Curtis 1956). At each site, 6 transects were established. These transects were in addition to those described above to measure abundance of contacting partners, but their spatial distribution among rocky outcrops was similar. A total of 40 quadrats were randomly placed along each transect. The clump of $M$. laminarioides or $N$. fastigiata closest to the central point of each quadrat was used as the reference individual. The distance between the holdfast of this individual and the base of its nearest inter- or intraspecific neighbor was then measured to the nearest $0.1 \mathrm{~mm}$ using a vernier caliper. The 240 values measured at each site were then used to calculate frequency distribution of inter-clump distances in each population. Inter-site and inter-species comparisons of inter-clump distances were performed using Kolmorov-Smirnov tests (Siegel \& Castellan 1988).

Spatial distribution of fronds: To determine the effects of contact with a partner on the spatial distribution and frequency of frond size, we monitored 15 clumps of Mazzaella laminarioides before and after holdfast contact with conspecifics. We established a line transect along the basal disk of each clump and measured the height and position of each frond along the transect. Position was defined as the distance from the individual frond to the end of the holdfast. After clumps of $M$. laminarioides coalesced, measurements were repeated every month to the end of the study period (350 d in the oldest clumps). To standardize frond differences due to overall size, frond height $( \pm 0.01 \mathrm{~cm})$ was expressed as the height $(\%)$ relative to the longest frond of each transect. The relative position of the frond along the transect was expressed as the percentage of distance from one end of the transect $(0 \%)$ to the other $(100 \%)$. The ordering of frond size distribution within clumps was tested using the non- 
parametric Jonckheere test (Siegel \& Castellan 1988). This test contrasts the trend of increase in values toward a certain direction of sampling (frond heights toward the center of the holdfast in this case) with a null hypothesis of absence of any trend.

Ultrastructural studies. To evaluate whether coalescence was occurring among inter- and intraspecific contacting partners, ultrastructural studies were undertaken. Characterization of the process of coalescence at the cellular level followed (with modifications) the protocol described in previous studies

\section{Maitencillo}

M. laminarioides (no neighbor within $2 \mathrm{~mm}$ )

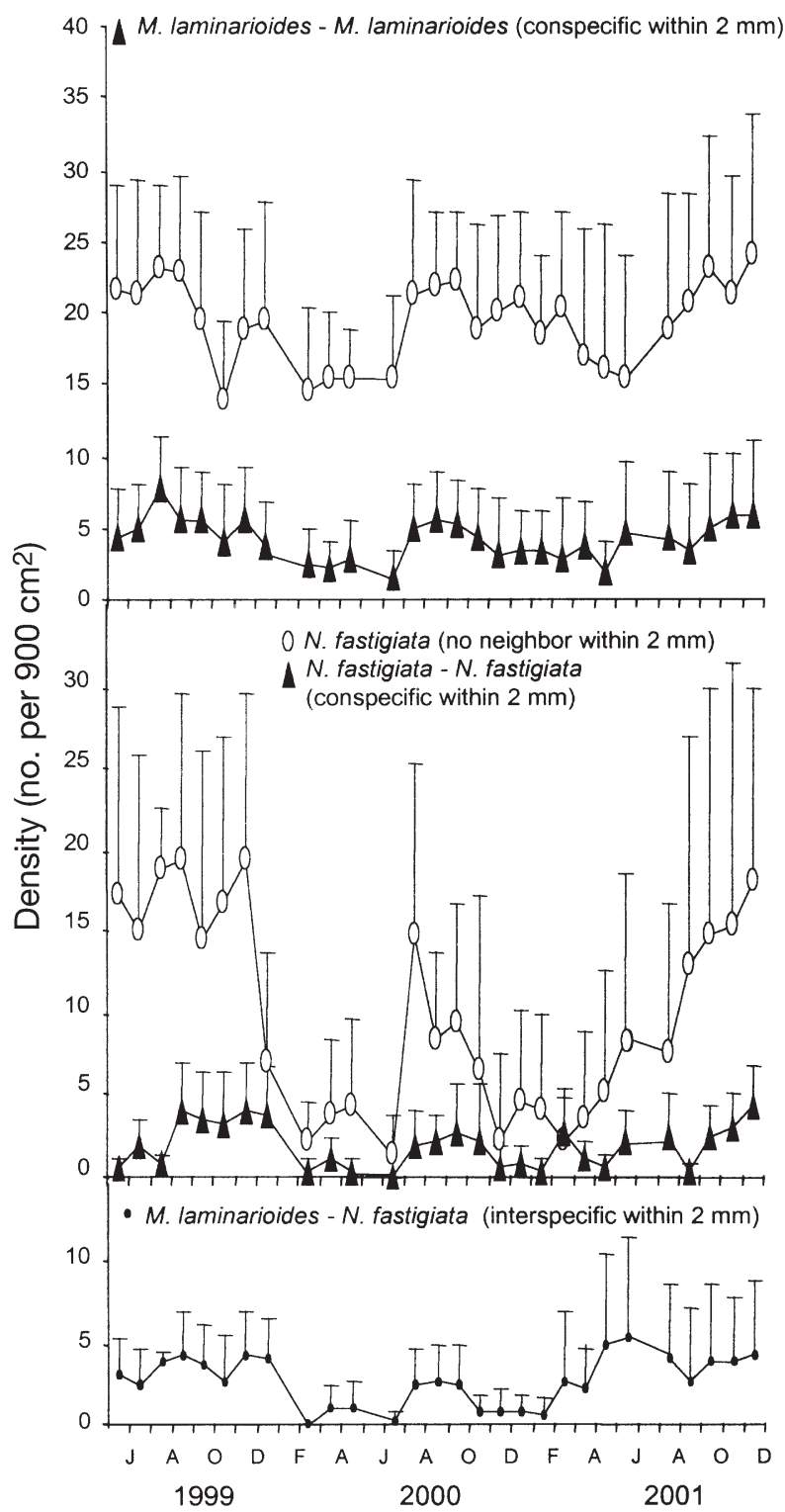

(Santelices et al. 1996, 1999). Contacting holdfasts were carefully removed from the rocks about $30 \mathrm{~d}$ after contact, and fixed in the field for ultrastructural analysis. Tissues were fixed at $15^{\circ} \mathrm{C}$ in $5 \%$ glutaraldehyde and $3 \%$ acrolein in water for $3 \mathrm{~h}$ under vacuum. Dehydration, embedding and infiltration were standard (see Santelices et al. 1996). Thin sections were stained with $4 \%$ uranyl acetate and lead citrate according to Reynolds (1963) and were observed with a JEOL 100SX electron microscope operated at $60 \mathrm{kV}$.

\section{Topocalma}

$0 \mathrm{M}$. laminarioides (no neighbor within $2 \mathrm{~mm}$ )

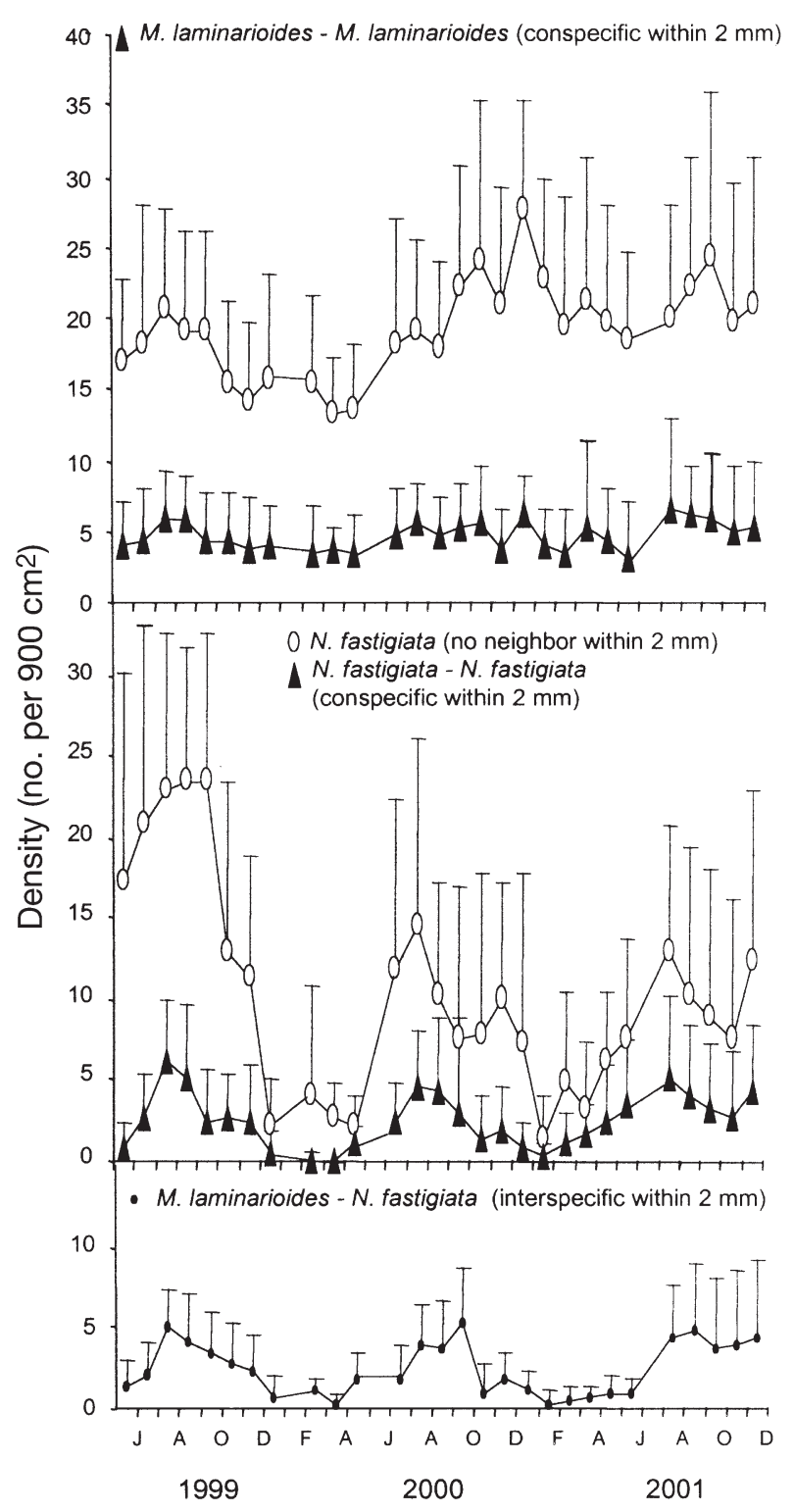

Fig. 1. Mazzaella laminarioides and Nothogenia fastigiata. Mean clump density at the 2 study sites, grouped according to number of clumps with and without neighboring disks within $2 \mathrm{~mm}$. Bars $=\mathrm{SE}$ 


\section{RESULTS}

\section{Contacting partners}

Clumps of Mazzaella laminarioides and Nothogenia fastigiata in contact with interspecific or conspecific partners (0 to $2 \mathrm{~mm}$ of inter-holdfast distance) were found at all times at both sites (Fig. 1). At Maitencillo, the density of $M$. laminarioides varied from 15 to 35 clumps per $900 \mathrm{~cm}^{2}$ of rock surface. At any time of the year, 20 to $25 \%$ of these clumps ( 3 to 9 clumps) were in contact with conspecific holdfasts, while 10 to $20 \%$ (1 to 7 clumps) were in contact with interspecific clumps. The remaining 60 to $75 \%$ of the clumps were free of contact as their nearest-neighbor distance was $>2 \mathrm{~mm}$.

Similar situation was found for the clumps of Nothogenia fastigiata at this site (Fig. 1). Clump density of this species was 10 to 20 clumps per $900 \mathrm{~cm}^{2}$. Between 3 and 5 of these clumps (15 to $30 \%$ ) were in contact with conspecific plants, while 2 to 4 (10 to $20 \%$ ) were in contact with interspecific partners. Even during the austral summer and autumn, when N. fastigiata lost its erect axes (February to August 2000, January to May 2001), encounters between holdfasts persisted.

The results for Topocalma revealed a similar pattern for both species (Fig. 1). They also suggested that at all times of the year 15 to $25 \%$ of the clumps in the populations of both species are in contact with either interor intraspecific partners.

\section{Temporal changes in holdfast dimensions}

Holdfast growth of both species in the field was strictly seasonal and restricted to late winter and spring (Fig. 2). In these seasons, holdfast expansion was as much as $4 \mathrm{~mm} \mathrm{mo}^{-1}$ in Mazzaella laminarioides and $2 \mathrm{~mm} \mathrm{mo}^{-1}$ in Nothogenia fastigiata. During summer and fall, the holdfasts of both species stopped growing and, in some cases, even showed reductions in size.

Monitoring of tagged clumps indicated that neighbors separated by as much as $33 \mathrm{~mm}$ can eventually reach a neighboring clump, establishing inter- or intraspecific contacts. Over the study period, a total of 218 pairs of conspecific clumps of Mazzaella laminarioides in close proximity were tagged at the 2 study sites (Table 1). Of these pairs, $51 \%$ (112) were lost before contact between the 2 clumps. A total of 35 of the remaining 106 tagged pairs (33.1\%) established intraspecific contact over the study period. Of these coalesced pairs, $16(45.7 \%)$ were lost after coalescence either because the holdfast was attacked by grazers, damaged by desiccation, or its continuity interrupted by recruiting mussels. All but one of the coalescing pairs were female gametophytes that produced cystocarps in the fertile season. The exception was a coalescing pair formed by a female gametophyte (haploid plant) and tetrasporophyte (diploid plant).

For Nothogenia fastigiata, the total number of closely located conspecific pairs tagged at both sites was 73 (Table 1) and 41 of these were lost before contact. Of

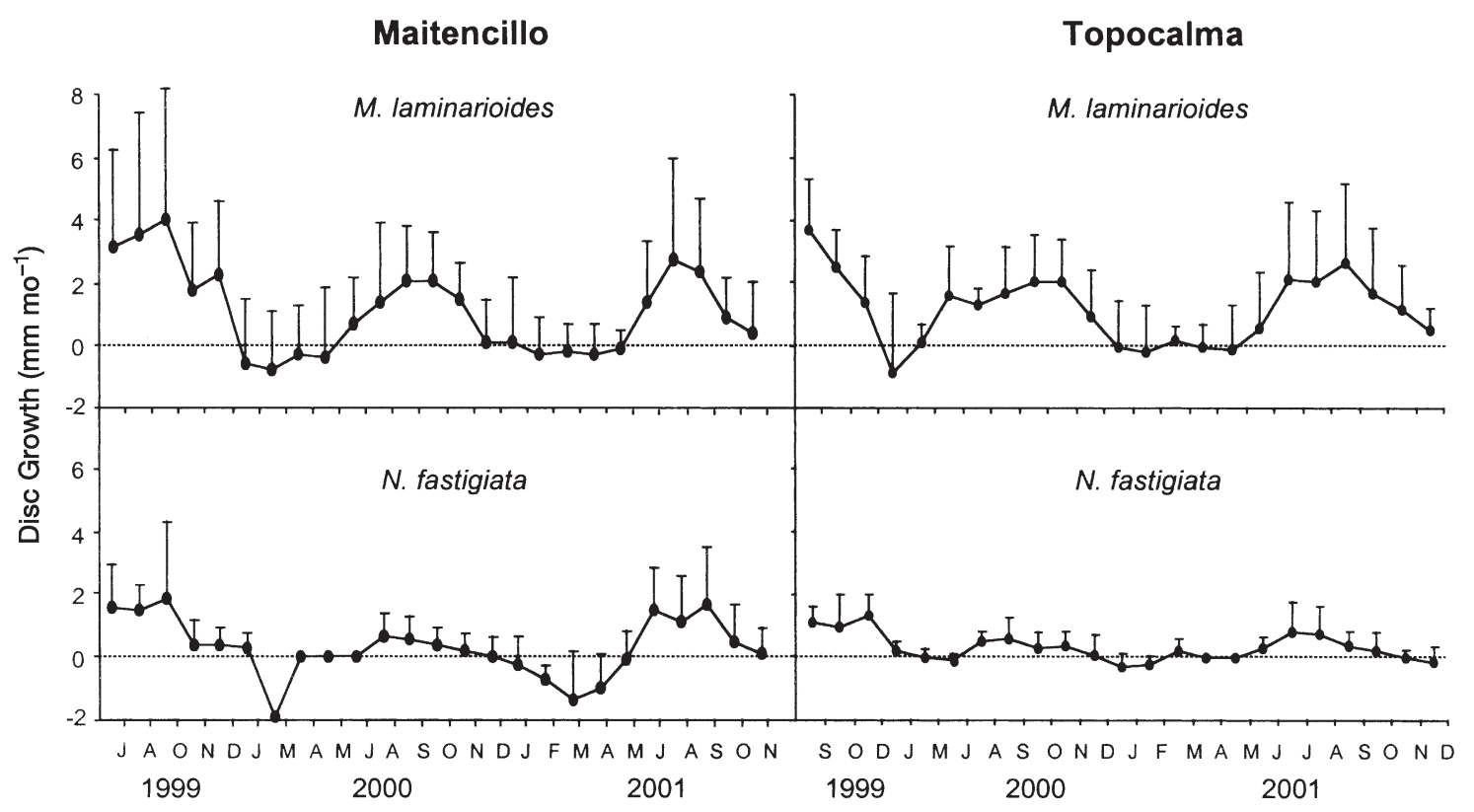

Fig. 2. Mazzaella laminarioides and Nothogenia fastigiata. Temporal changes in mean holdfast growth of tagged individuals in Maitencillo and Topocalma. Bars = SE 
the remaining 32 tagged gametophytes, 10 (31.25\%) established contact over the study period, 2 of which were lost in the following months.

Interspecific contacts between clumps of Mazzaella laminarioides and Nothogenia fastigiata were based on an initial 71 pairs of clumps at both sites (Table 1). A total of 42 of these clumps was lost before contact, while 6 of the remaining 29 (20.1\%) established contact during the study period. In all cases, clumps of $N$. fastigiata were overgrown by $M$. laminarioides and the 6 contacting partners were lost in the following 6 mo.

The time required by tagged pairs of clumps to establish contact was a function of the initial interholdfast distance (Fig. 3). To establish contact within the 6 mo growth season throughout central Chile, conspecific partners of Mazzaella laminarioides and Nothogenia fastigiata must initially be $<10$ or $5 \mathrm{~mm}$ apart respectively. Similarly, interspecific partners initially $<7 \mathrm{~mm}$ apart established contact within a single growing season. Relatively distant pairs of $M$. laminarioides that survived and grew during a second season bridged inter-holdfast distances of 18 to $20 \mathrm{~mm}$ (Fig. 3).

\section{Inter-clump distances}

The frequency distributions of inter-clump distances differed significantly between species (Kolmogorov-

Table 1. Mazzaella laminarioides and Nothogenia fastigiata. Total number of pairs of clumps tagged, lost and coalescing during study period. $(\%)$ = percentage of total no. tagged

\begin{tabular}{|c|c|c|}
\hline & Maitencillo & Topocalma \\
\hline \multicolumn{3}{|c|}{ M. laminarioides-M. laminarioides interactions } \\
\hline Total no. of tagged pairs & 127 & 91 \\
\hline Lost before contact & $68(53.5 \%)$ & $44(48.4 \%)$ \\
\hline Available pool of tagged pairs & 59 & 47 \\
\hline Coalescing & $16(27.1 \%)$ & $19(40.4 \%)$ \\
\hline Remaining apart & $43(72.8 \%)$ & $28(59.6 \%)$ \\
\hline Lost after coalescence & $6(37.5 \%)$ & $10(52.6 \%)$ \\
\hline \multicolumn{3}{|c|}{ N. fastigiata-N. fastigiata interaction } \\
\hline Total no. of tagged pairs & 34 & 39 \\
\hline Lost before contact & $20(58.8 \%)$ & $21(53.8 \%)$ \\
\hline Available pool of tagged pairs & 14 & 18 \\
\hline Coalescing pairs & $2(14.2 \%)$ & $8(44.4 \%)$ \\
\hline Remaining apart & $12(85.7 \%)$ & $10(55.4 \%)$ \\
\hline Lost after coalescence & $0(00.0 \%)$ & $2(25.0 \%$ \\
\hline \multicolumn{3}{|c|}{ M. laminarioides $-N$. fastigiata interaction } \\
\hline Total no. of tagged pairs & 46 & 25 \\
\hline Lost before contact & $30(65.0 \%)$ & $12(48.0 \%)$ \\
\hline Available pool of tagged pairs & 16 & 13 \\
\hline Coalescing pairs & $3(18.8 \%)$ & $3(23.07 \%)$ \\
\hline Remaining apart & $13(81.2 \%)$ & $9(69.2 \%)$ \\
\hline Lost after coalescence & $3(100.0 \%)$ & $3(75.0 \%$ \\
\hline
\end{tabular}
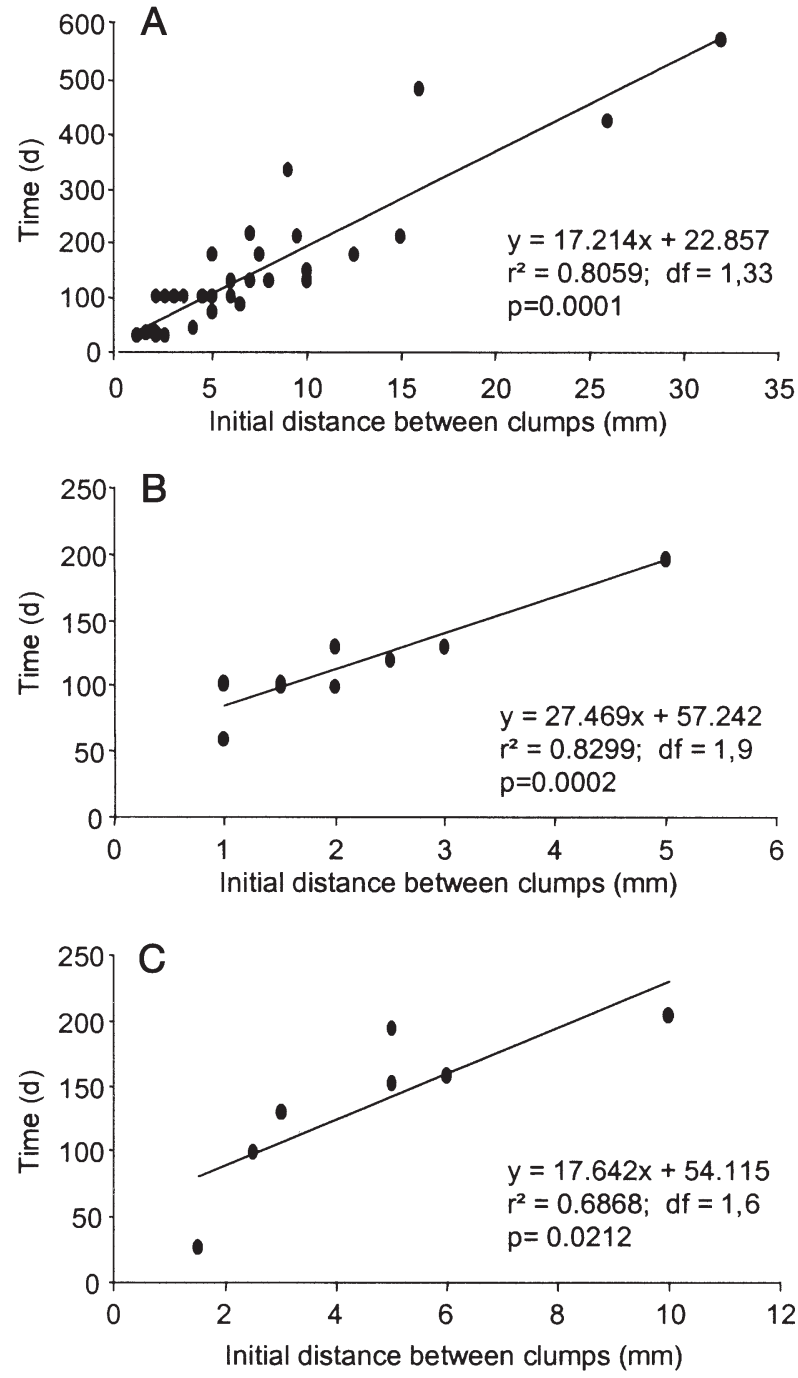

Fig. 3. Mazzaella laminarioides and Nothogenia fastigiata. Time needed to establish contact as a function of initial distance for intraspecific contacts of (A) M. laminarioide, (B) $N$. fastigiata and (C) for interspecific contacts between both species

Smirnov 2-sample test: $D_{\max }=0.430, \mathrm{p}<0.0001$ for the Maitencillo population and $D_{\max }=0.397, \mathrm{p}=0.001$ for the Topocalma population), but each species presented a similar pattern of distribution at the 2 sites (Kolmogorov-Smirnov 2-sample test, $D_{\max }=0.051, \mathrm{p}=0.43$ for Mazzaella laminarioides and $D_{\max }=0.191, \mathrm{p}=0.194$ for Nothogenia fastigiata) (Fig. 4). Neighboring clumps of conspecific $M$. laminarioides were not strongly aggregated, while $N$. fastigiata clumps were most frequently found living close $(<15 \mathrm{~mm})$ to their neighbors, regardless of specific identity of the neighbor (conspecific or interspecific).

The data results on the frequency distribution of inter-clump distances indicate that $18 \%$ of the population of Mazzaella laminarioides at Maitencillo and 

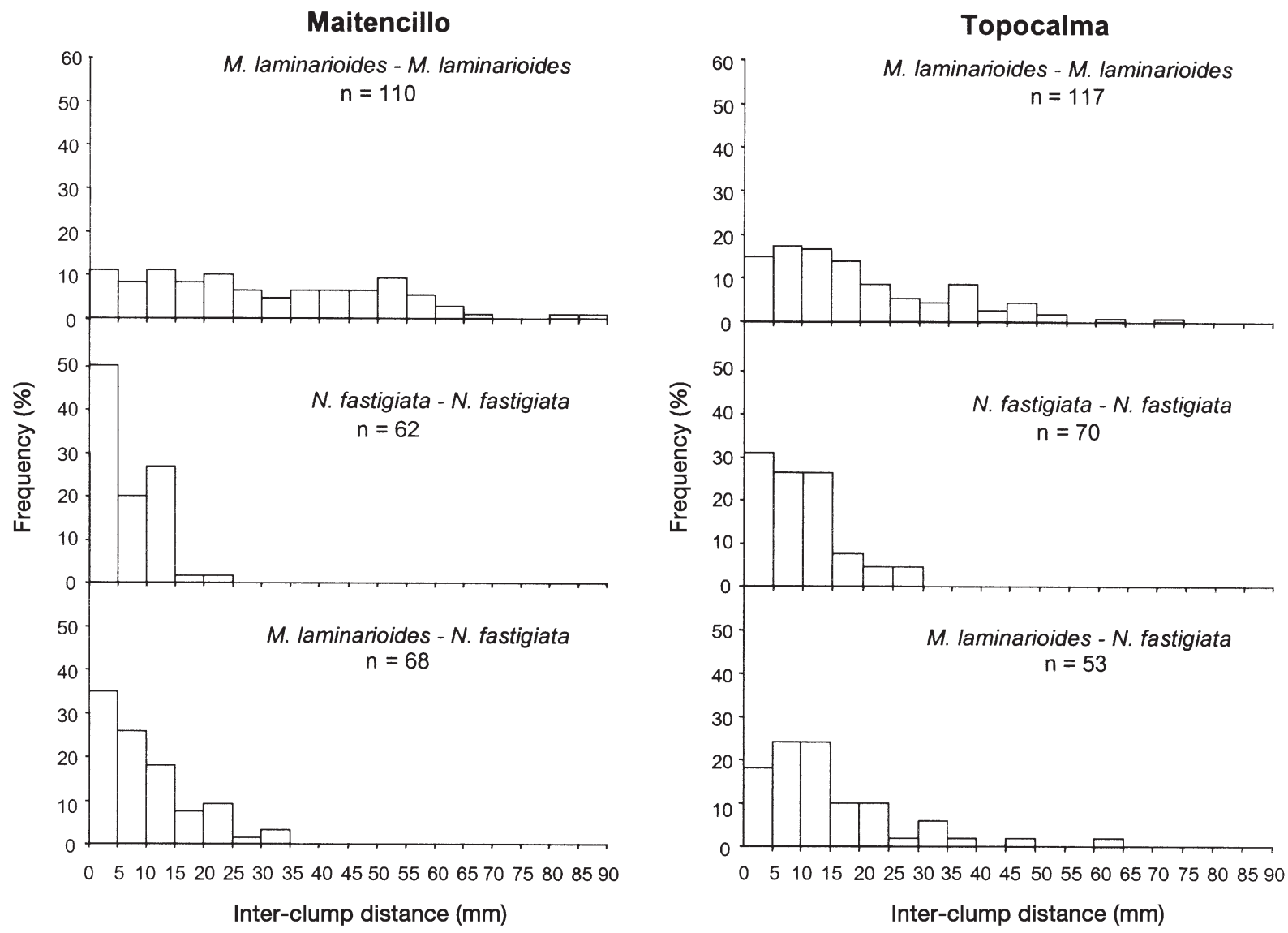

Fig. 4. Mazzaella laminarioides-Nothogenia fastigiata. Frequency distributions of inter-clump distances in seaweed belt in Maitencillo and Topocalma. Data have been grouped as inter- and intraspecific distances

$32 \%$ of the population at Topocalma exhibited interclump distances of $<10 \mathrm{~mm}$. Equivalent data for Nothogenia fastigiata indicate that $45.7 \%$ of the Maitencillo population and $28.2 \%$ of the Topocalma population had conspecific pairs located at distances of $<5 \mathrm{~mm}$. On the other hand, the frequency distribution of the interspecific distances indicates that $47 \%$ of the interspecific pairs in Maitencillo and $29.3 \%$ of those in Topocalma occurred at distances of $<7 \mathrm{~mm}$ apart.

\section{Spatial distribution of fronds}

Responses of fronds to the coalescence of clumps could only be followed in Mazzaella laminarioides because post-reproduction losses of erect axes prevented similar studies in Nothogenia fastigiata. Individual clumps of $M$. laminarioides were characterized by longer erect blades towards the center of the clump and shorter axes towards the margins (e.g. Clumps 119a and 119b in Fig. 5). After intraspecific contact and coalescence, the coalescing borders of the holdfast became the central part of the new clump (e.g. Clumps 119a and 119b in Fig. 5). Short erect axes on the border of the separate holdfasts before coalescence started growing upon coalescence, and about 90 to $120 \mathrm{~d}$ after coalescence, the now larger holdfast had recovered its original shape, exhibiting short erect axes at its margins and longer erect axes towards its center. These frond responses to coalescence were observed in 15 of the 19 coalescing pairs of $M$. laminarioides that survived to the end of the study.

\section{Ultrastructure}

The 6 clumps of Nothogenia fastigiata that established interspecific contact with 6 clumps of Mazzaella laminarioides (e.g. Fig. 6a) persisted 3 to 6 mo in the field after initial contact. In all cases, the basal crust of $N$. fastigiata was overgrown by the base of the M. laminarioides clump (Fig. 6b). Microscopic examination of the areas of contact (Fig. 6c,d) revealed a thick interface of necrotic tissues in both species. Cell-wall remains, crushed cells and even cyanobacterial nodules were found in the contact zone. 

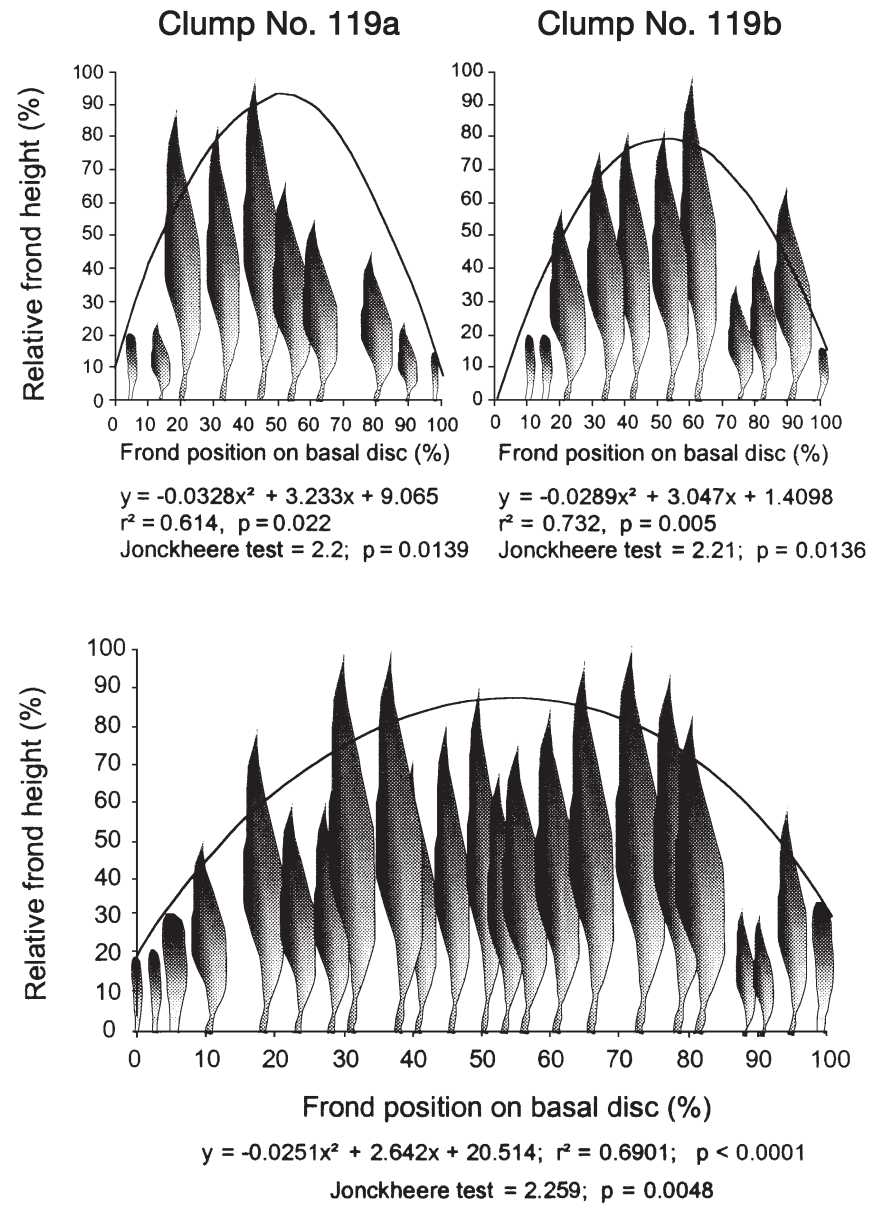

Fig. 5. Mazzaella laminarioides. Change in shape of clumps before and after coalescence. Diagram represents the specific case of Clumps 119a and 119b before coalescence (top graphs) and $90 \mathrm{~d}$ after coalescence (bottom graph, combined data)

The 35 pairs of Mazzaella laminarioides and the 10 pairs of Nothogenia fastigiata that established contact with conspecifics during the study period formed a macroscopically continuous holdfast within 1 mo after coalescence. These coalesced clumps persisted to the end of the study period.
Intraspecific contacts in Mazzaella laminarioides took place by border expansion of the basal crust. These marginal outgrowths do not necessarily occur around the whole periphery of the disc, and they often appear as purple, thin and delicate membranous expansions extending from 1 side of the disc over the substratum. These extensions often grow in the shade of the erect canopy. After coalescence, new erect axes appear in the contact area (Fig. 6e). In 3 of the 35 coalescence events observed in $M$. laminarioides, healing scars (Fig. 6f) persisted in the contact zone. Healing scars appeared as pale linear marks that persisted at the position where the holdfasts first made contact. They were absent from the new tissue produced after coalescence.

Intraspecific contact in Nothogenia fastigiata also took place by border expansions of the basal crust. Since these crusts are thin, the outgrowths were difficult to identify in the field. More often, individual holdfasts were observed approaching each other (Fig. 6g), and most of the encounters ( 8 out of 10 in the study period) left a pale healing scar in the contact zone.

Microscopic examination of the coalescing tissues in both species showed the absence of thick interfaces or necrotic tissues between intraspecific partners (Fig. 6h,i). In the case of Mazzaella laminarioides, the 2 adjacent crusts exhibited some intertwining of growth filaments in the contact zone (Fig. 6h). Nothogenia fastigiata growth filaments were extensively intertwined at the zone of contact (Fig. 6i). In both species, the areas with healing scars (Fig. 6j) exhibited small subsquare cells, suggesting rapid growth of filaments where the conspecifics first contacted each other.

Transmission electron microscopy examination of the contact zones of Mazzaella laminarioides and Nothogenia fastigiata in interspecific encounters confirmed damage to the contacting cells. Cell walls were thickened and organelles were abnormal, especially in the cells of $N$. fastigiata (Fig. 7a,b). Secondary pit connections were absent, even in places where the cells of different partners were in close proximity (Fig. 7c). In

Fig. 6. Mazzaella laminarioides (M.l.) and Nothogenia fastigiata (N.f.). Inter- and intraspecific encounters. (a) Clumps of both species with contacting disks; scale bar $=1 \mathrm{~cm}$. (b) Cross-section of contacting disks of $M$. laminarioides and N. fastigiata. Basal crust of $M$. laminarioides (thin arrows) has overgrown base of $N$. fastigiata and is climbing along erect axes (thick arrow); scale bar $=$ $0.5 \mathrm{~mm}$. (c) Section through erect axis of $N$. fastigiata (on left) covered by M. laminarioides (on right); note thick interface in the contact zone of the 2 partners (arrows); scale bar $=40 \mu \mathrm{m}$. (d) Longitudinal section of 2 contacting crusts of $M$. laminarioides (lower section) and N. fastigiata (upper section); note thick interface with cell walls and other cell remains (arrows) resulting in cell destruction for both partners; scale bar $=20 \mu \mathrm{m}$. (e) Intraspecific coalescence in $M$. laminarioides; new erect axes are being formed in coalesced area (arrow) 60 to $90 \mathrm{~d}$ after contact between Clumps 1 and 2; scale bar $=1 \mathrm{~cm}$. (f) Evidence of healing scar (arrows) in contact zone between 2 coalescing holdfasts of $M$. laminarioides; erect axes have been sectioned; scale bar $=1 \mathrm{~mm}$. (g) Intraspecific coalescence among crusts of $N$. fastigiata (thin arrows); note also contact zone between M. laminarioides and $N$. fastigiata (thick arrow); scale bar $=2 \mathrm{~mm}$. (h) Longitudinal section of 2 coalescing crusts of M. laminarioides; note larger intercellular spaces (arrows) between Crusts 1 and 2; scale bar $=40 \mu \mathrm{m}$. (i) Longitudinal section of coalescing crusts of $N$. fastigiata; note intertwining of filaments in coalescing area between Crusts 1 and 2; scale bar $=40 \mu \mathrm{m}$. (j) Longitudinal section of healing scar in N. fastigiata; note subsquare cells extending between the 2 coalescing fronts; scale bar $=20 \mu \mathrm{m}$ 


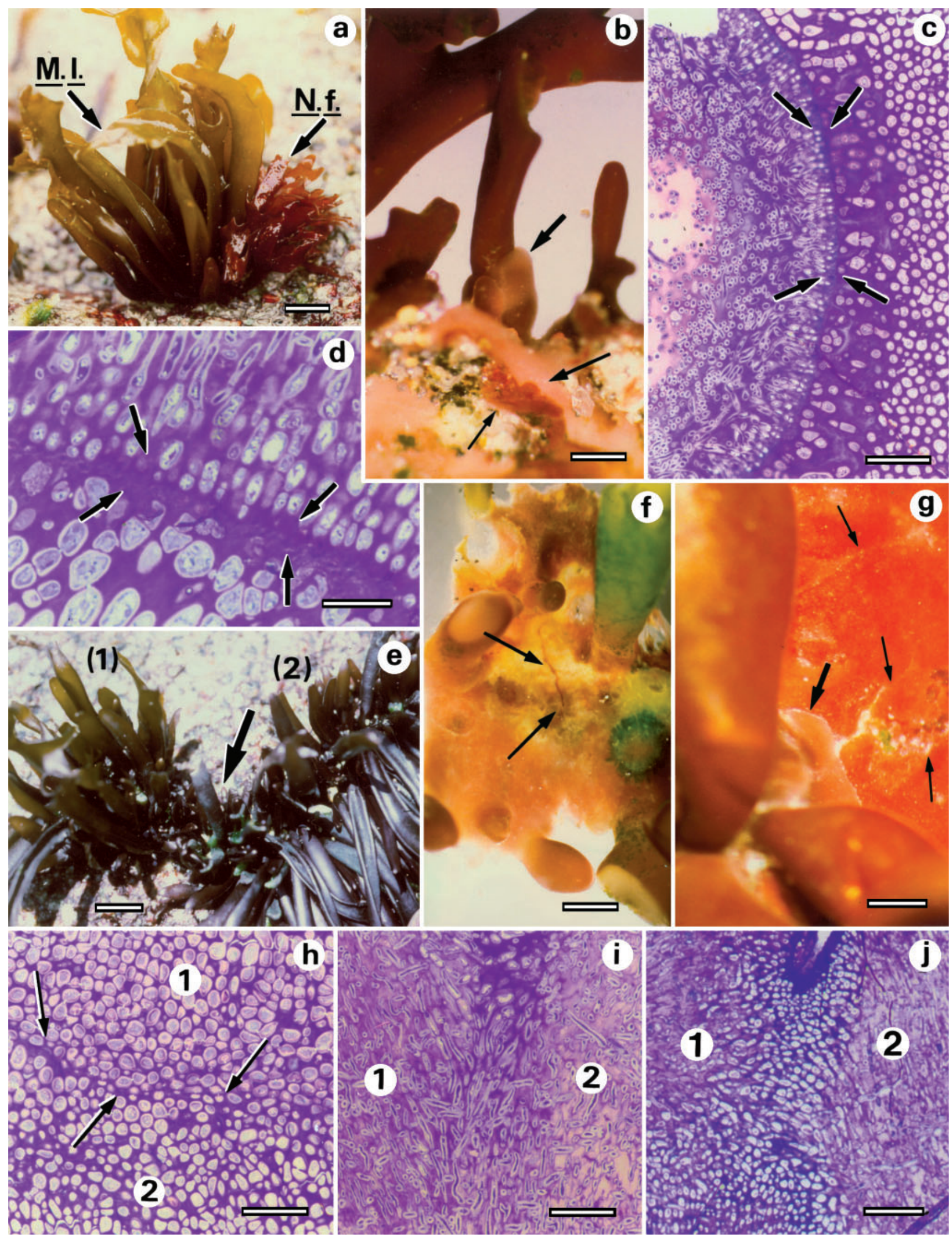



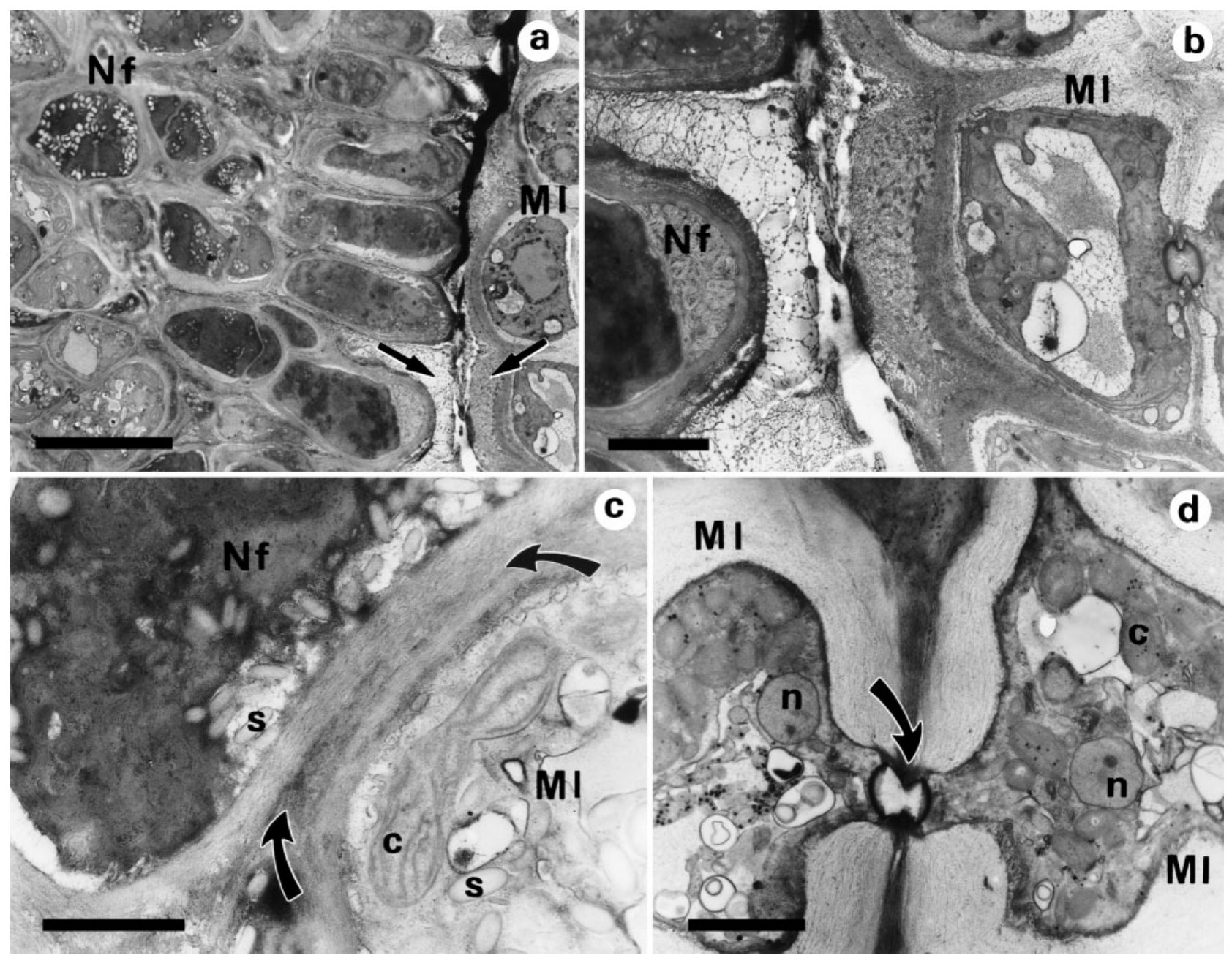

Fig. 7. Mazzaella laminarioides (M.l.) and Nothogenia fastigiata (N.f.). Cellular structure in inter- and intraspecific contacts. (a) Contacting border (arrows) in interspecific contact; note thickened cell walls of both partners and cell destruction in the first 2 to 3 rows of cells of $N$. fastigiata; scale bar $=10 \mu \mathrm{m}$. (b) Close-up of contacting border; scale bar $=3 \mu \mathrm{m}$. (c) Close-up showing a absence of secondary pit connections in contacting cells of $N$. fastigiata and M. laminarioides; arrows indicate contacting zone; scale bar $=1 \mu \mathrm{m}$. (d) Intraspecific coalescence in $M$. laminarioides; contacting cells developed secondary pit connections (arrow) some $60 \mathrm{~d}$ after coalescence; scale bar $=2 \mu \mathrm{m}$. c: chloroplast, n: nucleus, s: starch grains

contrast, cells in intraspecific contact showed secondary pit connections between the 2 species (Fig. 7d).

\section{DISCUSSION}

Given that coalescence in seaweeds has long been recognized, is known to occur in the laboratory among diverse and widespread taxa, and is thought to have important biological consequences, it is surprising that almost nothing is known about the occurrence or dynamics of coalescence in the field. Basic descriptive field studies are scarce, probably because previous coalescence studies have focused exclusively on spores and germlings, which are difficult to study in the field, and because there is no way to visibly confirm whether a given individual is in fact a product of one or more genotypes after coalescence has occurred. This deficiency has limited our ability to determine the relative importance of coalescence in natural populations. Here, we report a unique set of studies describing monthly and seasonal variation in the potential for coalescence in populations of 2 midintertidal algae species observed over $2.5 \mathrm{yr}$ at 2 sites along the central Chile coast. Moreover, we illustrate the dramatic contrast between inter- and intraspecific contacts and evaluate the impacts of coalescence between conspecifics on the distribution and growth of fronds and on the resulting shape of the coalesced clump. 
The combination of field and histological results indicates that coalescence does occur naturally in midintertidal populations of Mazzaella laminarioides and Nothogenia fastigiata. Here we give the first description of naturally occurring coalescence in the field and demonstrate, for the first time, coalescence between holdfasts of well-established algae clumps. All previous studies on coalescence (reviewed by Santelices et al. 1999) have documented the process among sporelings growing in laboratory cultures only.

Although interspecific coalescence has been reported from laboratory cultures of 2 Gracilaria species (Maggs \& Cheney 1990), we found that coalescence occurred only among conspecific partners in the field. Contact between interspecific partners produced tissue destruction at the contacting borders of the 2 crusts, as attested by thick necrotic tissues composed of crushed cells and cell-wall remains of both species. The different holdfast growth rates of the 2 species (e.g. Figs. 2 \& 3) seem to be responsible for this cell compression and destruction. Thus, because the 2 species are unable to coalesce, interspecific competition appears to be the main interaction between the 2 dominant seaweeds in these vegetational belts. It should be noted, however, that the factors and mechanisms involved in this competitive interaction, as well as experiments to demonstrate competition (Underwood \& Denley 1984, Denley \& Dayton 1985, Underwood 1986, 2000), were beyond the scope of the present study.

The thick necrotic interface developed between the contacting cells of the 2 species might also be explained by other factors such as histocompatibility. However, basic experimental data of interspecific histocompatibility responses among seaweeds are scarce. Koslowsky \& Waaland $(1984,1987)$ showed that different geographic isolates of Griffithsia pacifica exhibit incompatibility during cell fusion, causing cytoplasmic swelling, protoplasm agglutination and chloroplast degradation in the more sensitive strain. However, as far as we know, coalescence does not involve cell fusion, but mostly regulation and compatibilization of cell and filament growth.

Our field results suggest that coalescence between conspecifics is a frequent process in the field. Combining the length of the growing season, the growth rates of the tagged holdfasts and the frequency distribution of the nearest conspecific neighbors, 18 to $32 \%$ of the clumps of Mazzaella laminarioides and between 28 and $46 \%$ of Nothogenia fastigiata clumps could establish conspecific contacts, and eventually coalescence, within a growing season. If 2 growing seasons in consecutive years are considered, the probabilities rise to $37-64 \%$ for M. laminarioides and $54-84 \%$ for $N$. fastigiata. The growth rates exhibited by the holdfasts of these species would allow the plants to cover all interclump distances by the accumulated growth of 6 to $8 \mathrm{yr}$ for M. laminarioides and 5 to 6 yr for $N$. fastigiata.

Given the above data, one would expect that, a few years after being established, the populations of these coalescing seaweeds would be comprised of a few, large, extensive clumps with an almost continuous base. However, these are not found in the field, suggesting that coalescence is modulated by the effect of other community processes. During summer and early fall, the holdfasts of both species stops growing and, in some cases, even exhibit reductions in size. Our field observations indicate that abiotic extremes such as high temperature and desiccation, grazing, and mussel recruitment may determine discontinuities in the holdfasts of coalesced clumps.

While this study has shown that coalescence occurs between pairs of adult plants, it is as yet unknown at which stage of population development coalescence is most important. Many seaweeds disperse aggregated propagules, often with a sticky, mucilaginous envelope around the spores (see Santelices 1990b and Norton 1992 for reviews). In addition, field experiments have shown aggregated recruitment in several red algae species (Santelices et al. 1996, 1999). Therefore, coalescence during recruitment and other early stages of population establishment is probably more frequent than among fully grown, well-established individuals. At those early stages of population development, coalescence seems to replace intraspecific competition, the latter of which is an important mortality factor in the establishment of non-coalescing seaweed populations (e.g. Chapman \& Goudey 1983, Santelices \& Ojeda 1984, Dean et al. 1989, Reed 1990, Ang \& DeWreede 1993, Flores-Moya et al. 1997, Creed et al. 1998, Scrosati 2000). To gain a better understanding of the relative importance of coalescence as a community process, as well as to develop new demographic models for coalescing seaweeds (Santelices 2001), future experimental studies should explore the relationships among coalescence, intraspecific competition and recruitment at different population densities.

After coalescence, the merging borders of the interacting clumps become the new center of the coalesced clump. Prior to coalescence, the erect fronds at the merging borders are typically short and dwarfed. After coalescence, these fronds develop longer and thicker erect axes which, eventually, become the largest fronds in the clumps. This creates size inequalities among fronds. These field results complement previous laboratory findings on size inequalities with various coalescing species (Santelices et al. 1999), and support the idea that size inequality could be a common morphological character among coalescing species with erect axes. As discussed elsewhere (San- 
telices et al. 1999), the factors producing size inequalities in these algae are unknown. Perhaps differential distribution of growth regulators associated with nutrient availability and differential translocation of photosynthates determines differential growth of one or a few more centrally located fronds which, in many coalescing species, are the first to mature or are the only fronds of the clump to produce propagules.

The field demonstration of coalescence in the 2 red algae species examined in this study suggests that many of these clumps may be chimeric organisms. However, no genetic data are yet available to establish the relatedness of coalescing clumps in the population studied. Among colonial animals, chimerism occurs in at least 9 phyla in several kingdoms (Buss 1982), and several benefits have been proposed for chimeric organisms compared with non-chimeric conspecifics. These include size increases, greater reproductive output, and greater genetic variability (Buss 1982, Grosberg \& Quinn 1986, Chornesky 1991, Rinkevich \& Weissman 1992, Maldonado 1998). In laboratory experiments with seaweeds, coalescence has been found to increase variability (Santelices et al. 1996), improve germination and recruitment, increase production because of a larger photosynthetically active canopy during growth, and increase reproduction due to unequal growth and concentration of energy in a few larger blades within a clump (Santelices et al. 1999).

Acknowledgements. We thank Evie Wieters for critical reading of the manuscript. Also we appreciate the grammatical help of Randy Finke and the support of FONDECYT, grant 1990160.

\section{LITERATURE CITED}

Ang PO, DeWreede RE (1993) Simulation and analysis of the dynamics of a Fucus distichus (Phaeophyceae, Fucales) population. Mar Ecol Prog Ser 93:253-265

Bancroft FW (1903) Variation and fusion of colonies in compound ascidians. Proc Calif Acad Sci (Zool) 3:137-186

Buss LW (1982) Somatic cell parasitism and the evolution of somatic tissue compatibility. Proc Natl Acad Sci USA 79: $5337-5341$

Chapman ARO, Goudey CL (1983) Demographic study of the macrothallus of Leathesia difformis (Phaeophyta) in Nova Scotia. Can J Bot 61:319-323

Chornesky EA (1991) The ties that bind: inter-clonal cooperation may help a fragile coral dominate shallow highenergy reefs. Mar Biol 109:41-51

Cottam G, Curtis JT (1956) The use of distance measures in phytosociological sampling. Ecology 37:451-460

Cottam G, Curtis JT, Hale BW (1953) Some sampling characteristics of a population of randomly dispersed individuals. Ecology 34:741-757

Creed JC, Kain JM (Jones), Norton TA (1998) An experimental evaluation of density and plant size in two large brown seaweeds. J Phycol 34:39-52
Dean TA, Thies K, Lagos SL (1989) Survival of juvenile giant kelp: the effects of demographic factors, competitors, and grazers. Ecology 70:483-495

Denley EJ, Dayton PK (1985) Competition among macroalgae. In: Littler MM, Littler DS (eds) Handbook of phycological methods. Ecological field methods: macroalgae. Cambridge University Press, Cambridge, p 512-530

Flores-Moya A, Fernández JA, Niell FX (1997) Growth pattern, reproduction and self-thinning in seaweeds: a reevaluation in reply to Scrosati. J Phycol 33:1080-1081

Giard A (1872) Recherches sur les ascides composees ou synascidies. Arch Zool Exp Gén I:501-704

Grosberg RK (1988) The evolution of allorecognition specificity in clonal invertebrates. Q Rev Biol 63:377-412

Grosberg RK, Quinn JF (1986) The genetic control and consequences of kin recognition by the larvae of a colonial marine invertebrate. Nature 322:456-459

Hoffmann AH, Santelices B (1997) Flora marina de Chile central. Ediciones Universidad Católica de Chile, Santiago

Hughes RN (1989) A functional biology of clonal animals. Chapman \& Hall, London

Jones WF (1956) Effect of spore coalescence on the early development of Gracilaria verrucosa (Hudson) Papenfuss. Nature (Lond) 178:426-427

Koslowsky D, Waaland S (1984) Cytoplasmic incompatibility following somatic cell fusion in Griffithsia pacifica Kylin, a red alga. Protoplasma 123:8-17

Koslowsky D, Waaland S (1987) Ultrastructure of selective chloroplast destruction after somatic cell fusion in Griffithsia pacifica Kylin (Rodophyta). J Phycol 23: 638-648

Maggs CA, Cheney DP (1990) Competition studies of marine macroalgae in laboratory culture. J Phycol 26:18-24

Maldonado M (1998) Do chimeric sponges have improved chances of survival? Mar Ecol Prog Ser 164:301-306

Martínez E, Santelices B (1992) Size hierarchy and -3/2 'power law' relationship in a coalescent seaweed. J Phycol 28:259-264

Mathieson AC, Nienhuis PH (eds) (1991) Intertidal and littoral ecosystems. Ecosystems of the world, Vol. 24. Elsevier, Amsterdam

Norton TA (1992) Dispersal by algae. Br Phycol J 27:293-301

Rafaelli D, Hawkins S (1996) Intertidal ecology. Chapman \& Hall, London

Reed DC (1990) An experimental evaluation of density dependence in a subtidal algal population. Ecology 71: $2286-2296$

Reynolds ES (1963) The use of lead citrate at high pH as an electron-opague stain in electron microscopy. J Cell Biol $17: 208-212$

Rinkevich B, Weissman IL (1992) Chimeras vs genetically homogeneous individuals: potential fitness costs and benefits. Oikos 63:119-124

Rosenvinge LK (1931) The marine algae of Denmark, contributions to their natural history. Part IV. Rhodophyceae, IV. Gigartinales, Rhodymeniales, Nemastomatales. K Dan Vidensk Selsk Skr 77:499-599

Santelices B (1990a) Patterns of organization of intertidal and shallow subtidal vegetation in wave exposed habitats of Central Chile. Hydrobiologia 192:35-57

Santelices B (1990b) Patterns of reproduction, dispersal and recruitment in the seaweed. Oceanogr Mar Biol Annu Rev 28:177-276

Santelices B (1991) Littoral and sublittoral communities of continental Chile. In: Mathieson AC, Nienhuis PH (eds) Intertidal and littoral ecosystems. Ecosystems of the world, Vol. 24. Elsevier, Amsterdam, p 347-370 
Santelices B (2001) Implications of clonal and chimeric-type thallus organization on seaweed farming and harvesting. J Appl Phycol 13:153-160

Santelices B, Ojeda P (1984) Recruitment, growth and survivorship of Lessonia nigrescens (Phaeophyta) at various tidal levels in exposed habitats of Central Chile. Mar Ecol Prog Ser 19:73-82

Santelices B, Norambuena R (1987) A harvesting strategy for Iridaea laminarioides in Central Chile. Hydrobiologia 151/152:329-333

Santelices B, Correa JA, Meneses I, Aedo D, Varela D (1996) Sporeling coalescence and intraclonal variation in Gracilaria chilensis (Gracilariales, Rhodophyta). J Phycol 32: 313-322

Santelices B, Correa J, Aedo D, Hormazábal M, Flores V, Sánchez P (1999) Convergent biological processes among coalescing Rhodophyta. J Phycol 35:1127-1149

Scrosati R (2000) The interspecific biomass - density relationship for terrestrial plants: where do clonal red seaweeds stand and why? Ecol Lett 3:191-197

Editorial responsibility: Anthony Underwood (Contributing Editor), Sydney, NSW, Australia
Siegel S, Castellan MJ (1988) Nonparametric statistics for the behavioral sciences. McGraw-Hill, New York

Sommerfeldt AD, Bishop JD (1999) Random amplified polymorphic DNA (RAPD) analysis reveals extensive natural chimerism in a marine protochordate. Mol Ecol 8:885-890

Stephenson TA, Stephenson A (1972) Life between tidemarks on rocky shores. WH Freeman, San Francisco, CA

Underwood AM (1986) The analysis of competition by field experiments. In: Kikkawa J, Anderson DJ (eds) Community ecology: patterns and process. Blackwell Scientific Press, Oxford, p 240-268

Underwood AJ (2000) Experimental ecology of rocky intertidal habitats: what are we learning? J Exp Mar Biol Ecol 250:51-76

Underwood AJ, Denley EJ (1984) Paradigms, explanations and generalizations in models for the structure of intertidal communities on rocky shores. In: Strong DR, Simberloff D, Abele LG, Thistle A (eds) Ecological communities: conceptual issues and the evidence. Princeton University Press, Princeton, NJ, p 151-180

Submitted: February 10, 2002; Accepted: December 19, 2002 Proofs received from author(s): March 10, 2003 